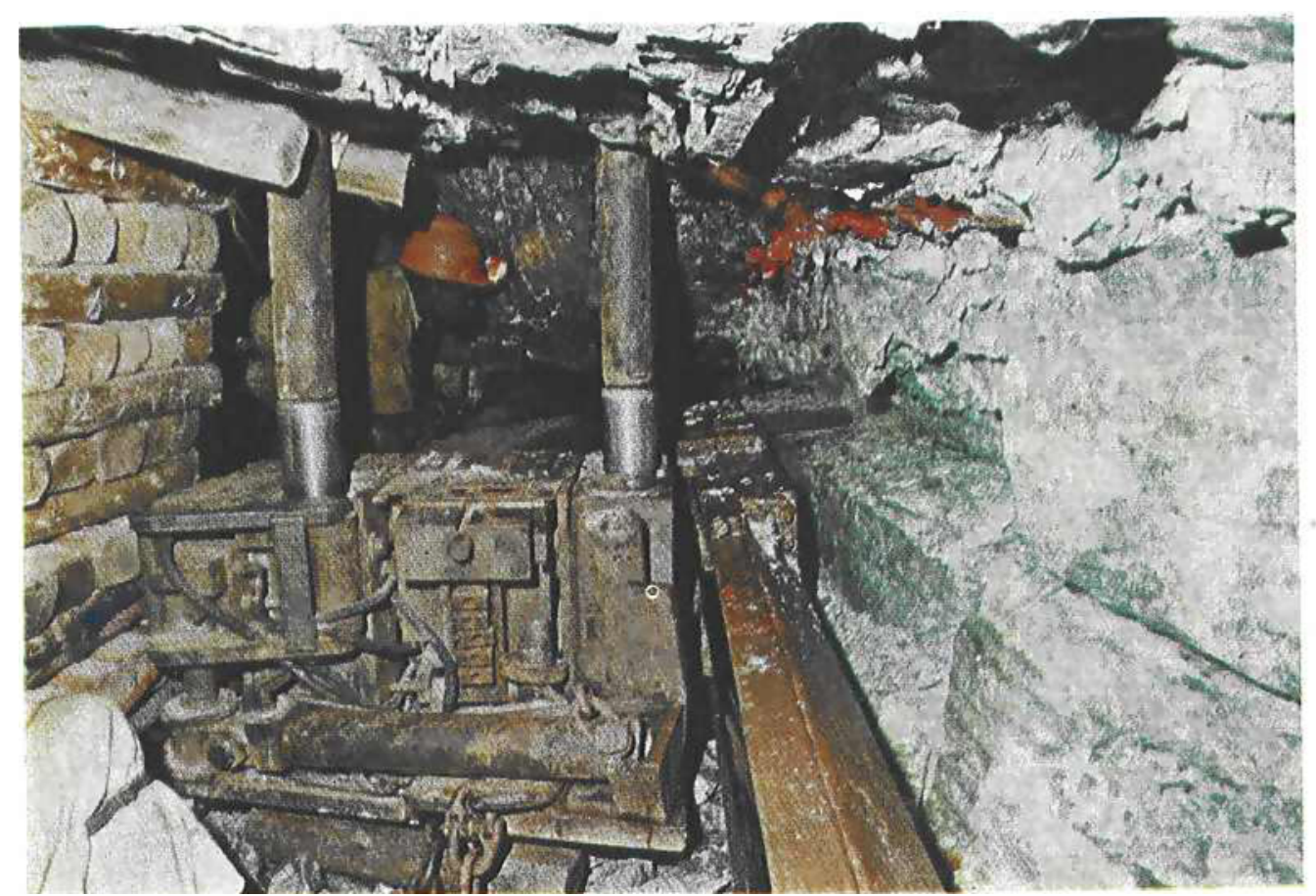

Over the past twenty to thirty years there has been a major break-through in coal-mining productivity through the introduction of mining systems using mechanised methods of excavation. The development of the equipment that will make it possible to use similar systems for excavating the hard quartzitic rocks of the Witwatersrand is a major objective and prototype rock-cutting machines, such as that shown here, have already excavated considerable areas of the gold-bearing reef in field trials. These and other developments are being vigorously pursued

Since current inflationary trends could nullify these effects, great importance is attached at present to increasing productivity in the industry in all spheres, and a campaign aimed at optimising the use of men, money, minerals, materials, and machinery throughout the industry is in progress. In the technical sphere, for example, a determined effort is being mounted to achieve major breakthroughs in the mechanical mining of the hard quartzitic reefs and in the control of rock stress and other environmental factors at depth. The efforts concentrated in this area recently by both the mining houses and the mines, and by the Research Organisation of the Chamber of Mines, are to be more than doubled.

In view of the success achieved in these areas to date, there is good reason to anticipate that gold will continue to flow from the mines of the Witwatersrand for very many years to come.

\title{
High Speed Gold Plating of Integrated Circuits
}

High yield with high reliability at low cost represent the ideal conditions for success in the production of beam lead integrated circuits. The selective gold plating of a wafer containing several hundred circuit chips is a critical part of the total processing in which a number of defects may give rise to rejections-lateral deposition of gold under the photoresist, too heavy or "spiky" deposition above the plane of the conductor paths, edge build-up, or non-adherence of the gold due to particles of photoresist depositing themselves on to a gold path or beam.

A new process aimed at providing a superior quality of gold plating with increased yield has been developed at Western Electric's Allentown Works and has been described by the engineer responsible for its initiation, Edward S. Figuli (Western Elect. Eng., 1974, 18, (1) 18-24). In this process, which has been given the, name "Velocity Gold Plating", a highly conductive electrolyte is used which permits of a considerable increase in current density. This is caused to impinge upon the surface to be plated at high speed, so that depletion of the cathode layer is avoided. Several electrolytes were investigated, but optimum results were obtained with an organic phosphate solution. A flow rate of around 8 litres per minute was found to be most satisfactory, but direct current plating was not so successful as a square wave periodic-reverse current; a ratio of forward to reverse current of about 30 to 1 gave the best results.

This high-speed method, now in production, has shown substantial improvements in chip per wafer yield-as much as 56 per cent greater than by normal plating practice-as well as greater ease of handling wafers and a shorter plating time. 